\title{
Ion transport membrane technology for the primary processing of natural gas
}

\author{
V. L. Kozhevnikov, I. A. Leonidov \& M. V. Patrakeev \\ Institute of Solid State Chemistry, Ural Branch of RAS, \\ Yekaterinburg, Russia
}

\begin{abstract}
Dense ceramic membranes with mixed, electron and oxygen-ion, conductivity are able to separate oxygen from air and other gas mixtures that contain oxygen in the form of individual molecules or gaseous oxides. This feature can be used in catalytic reactors in order to integrate oxygen separation and oxidation of gaseous organics. The method is currently considered as one of the most promising approaches for the development of novel energy efficient, environmentally friendly and compact technologies for processing of natural gas and related raw materials such as associated petroleum gas and biogas. The present report deals with general problems that emerge at practical implementations of ion-electron oxygen separating membranes in reactors for the primary processing of light hydrocarbons. The main demands for materials and process organization are considered. Particular attention is given to the partial oxidation of methane to synthesis gas.

Keywords: mixed conductors, oxygen flux density, ceramic membrane, partial oxidation of methane, selectivity, conversion, synthesis gas.
\end{abstract}

\section{Introduction}

At the current level of energy consumption, the coal and hydrocarbon reserves would be able to meet the requirement in energy for a foreseeable period of about a hundred years or little more. Therefore, along with the development of power engineering based on renewable resources and thermonuclear power, the efficient use of fossil energy resources and creating new resource-saving clean technologies, such as processes for conversion of hydrocarbons to more convenient energy carriers and chemical products, are becoming increasingly 
important. Due to high oil prices, the value of natural gas increases. Currently, the major part of the natural gas is burned to produce heat and electricity; some of it is consumed as automotive fuel. Only relatively small part of natural gas is chemically processed into products of organic and inorganic synthesis. Such inefficient use of the valuable raw material is largely due to imperfection of available methods of its processing. Currently the only method of methane processing that has practical significance is its conversion into synthesis gas, which represents a mixture of carbon monoxide and hydrogen and finds its use in a variety of synthetic processes. The most common method for production of synthesis gas is steam reforming of methane

$$
\mathrm{CH}_{4}+\mathrm{H}_{2} \mathrm{O}=\mathrm{CO}+3 \mathrm{H}_{2}, \Delta H_{298 \mathrm{~K}}^{0}=206.1 \mathrm{~kJ} \cdot \mathrm{mol}^{-1}
$$

The maintaining the reaction (1) requires large amount of heat. Therefore at least $40 \%$ of extra gas is burned for this. Moreover, the ratio of hydrogen and carbon monoxide is not suited for further use in methanol synthesis neither in the Fischer-Tropsch process. Therefore, additional treatment is required to improve the ratio of hydrogen to carbon monoxide. Thus, steam reforming of methane to synthesis gas is complicated in design and energy-intensive; the production cost equals $50 \%$ to $75 \%$ of the cost of the target products such as hydrogen, ammonia, methanol, liquid hydrocarbons, etc. [1]. An alternative method of synthesis gas production is partial oxidation of methane with the use of pure oxygen:

$$
\mathrm{CH}_{4}+0.5 \mathrm{O}_{2}=\mathrm{CO}+2 \mathrm{H}_{2}, \Delta H_{298 \mathrm{~K}}^{0}=-35.7 \mathrm{~kJ} \cdot \mathrm{mol}^{-1}
$$

The ratio of hydrogen to carbon monoxide in the resulting product is suitable for further processing. Moreover, quite a lot of heat is released in reaction (2), which is favourable for a compact implementation of the process. However the use of pure oxygen in process (2) is associated with problems of safety and considerable cost of oxygen. Some decades ago the promising method was proposed for separation of oxygen from air based on the use of high-temperature ceramic membranes with mixed electronic and ionic conductivity (MIEC). This method can be combined with catalytic processes of methane reforming to synthesis gas. The driving force of the oxygen separation is the difference between the partial pressures of oxygen in the gas half-spaces separated by the membrane. It is important to notice that oxygen is transported through the membrane in the ionic rather than in the molecular form; the electric neutrality of the membrane being provided by a counter-flow of electrons. The ionic mechanism of oxygen transfer determines $100 \%$ selectivity of the membrane with respect to oxygen. The membrane temperature should be within $800-1000^{\circ} \mathrm{C}$ to ensure its sufficiently high ionic conductivity. If one side of the membrane is in contact with methane and partial pressure $\left(p_{\mathrm{O}_{2}}^{\prime}\right)$ or activity of oxygen on it is low, whereas the other side of the membrane is in contact with air 
or other gas with high activity of oxygen $\left(p_{\mathrm{O}_{2}}^{\prime \prime}\right)$, then the driving force of the separation process will be the respective gradient of oxygen chemical potential. If surface exchange process is fast enough, the density of oxygen flux $\left(j_{\mathrm{O}_{2}}\right)$ through a MIEC membrane of thickness $d$ can be expressed through oxygen partial pressures at the opposite sides of the membrane and oxygen-ionic $\left(\sigma_{\mathrm{i}}\right)$ and electronic $\left(\sigma_{\mathrm{n}}\right)$ components of conductivity [2]

$$
j_{\mathrm{O}_{2}}=-\frac{R T}{16 F^{2} d} \int_{p_{\mathrm{O}_{2}}^{\prime}}^{p_{\mathrm{O}_{2}}^{\prime \prime}} \frac{\sigma_{\mathrm{i}} \cdot \sigma_{\mathrm{n}}}{\sigma_{\mathrm{i}}+\sigma_{\mathrm{n}}} d \ln p_{\mathrm{O}_{2}}
$$

where $R$ and $F$ are the universal gas constant and the Faraday constant, respectively. The catalytic membrane reactors attract much attention because they can significantly reduce the cost of synthesis gas production and, hence, the cost of products formed from it. Nonetheless, high demands to the materials used in such reactors still prevent the introduction of the technology in the industry.

\section{Materials for oxygen membranes}

The experiments show that cobalt-containing perovskite-like oxides $\mathrm{La}_{1-\mathrm{x}} \mathrm{Sr}_{\mathrm{x}} \mathrm{Co}_{1-\mathrm{y}} \mathrm{Fe}_{\mathrm{y}} \mathrm{O}_{3-\delta}$ have very high oxygen permeability [3, 4]. However, high oxygen transport parameters are not the only requirements to membrane materials for partial oxidation of methane (POM). The aim of the POM process is production of synthesis gas with the maximal fraction of valuable components $\left(\mathrm{H}_{2}\right.$ and $\left.\mathrm{CO}\right)$ and the minimal concentration of complete oxidation products $\left(\mathrm{H}_{2} \mathrm{O}\right.$ and $\mathrm{CO}_{2}$ ). Therefore this process should be realized under very severe reductive conditions, and the necessary feature of oxygen membranes is thermodynamic stability under such conditions. The cobalt-containing oxides do not meet these requirements as follows from the example in fig. 1. If stability under reductive conditions were used as the applicability criterion for membrane production for POM, the most suitable materials would be strontium ferrite $\mathrm{Sr}_{3} \mathrm{Fe}_{2} \mathrm{O}_{7-\delta}$ with Raddlesden-Popper structure and complex ferrites with perovskite structure. The stability boundary of ferrite $\mathrm{SrFeO}_{3-\delta}$ has a stage reflecting the perovskite to brownmillerite structure transition when the temperature lowers. Partial replacement of iron in this oxide by cation with a stable degree of oxidation $\left(\mathrm{SrFe}_{0.9} \mathrm{Nb}_{0.1} \mathrm{O}_{3-\delta}\right)$ leads to suppression of the phase transition and enhances the stability. Substituting lanthanum for strontium may also lead to increased stability since lanthanum ferrite exhibits the best stability among the oxides presented in fig. 1. In order to determine the range of materials suitable for membranes, we have been engaged in the last few years in fundamental research aimed at establishing the correlation between the composition, structure and transport characteristics of complex oxides. 


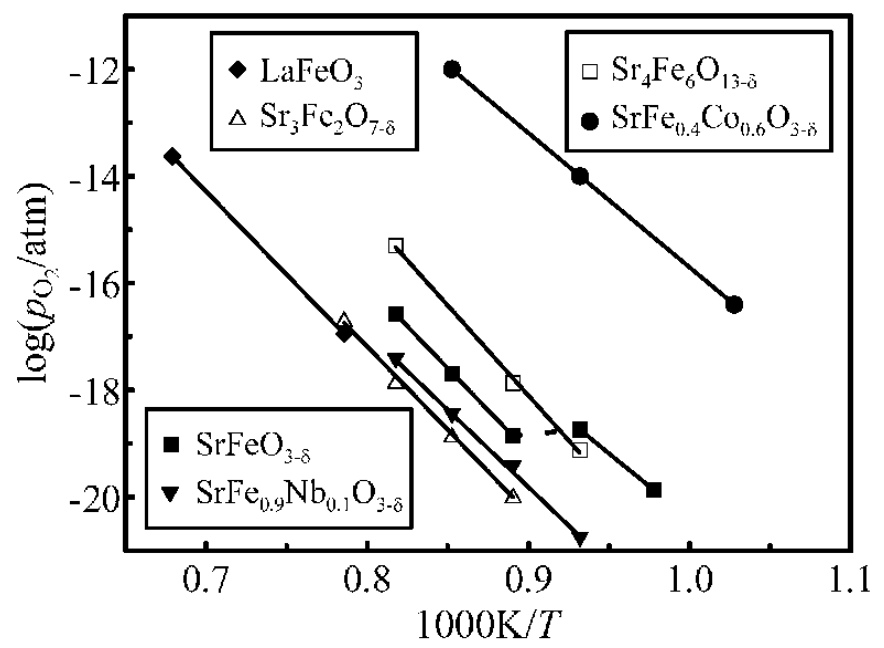

Figure 1: Low- $p_{\mathrm{O}_{2}}$ stability boundaries for complex ferrites. Data on $\mathrm{LaFeO}_{3-\delta}$ are results of work [5].

The basic method for examining the transport properties was measurement of total conductivity versus partial pressure of oxygen. The isothermal dependences of the conductivity in ferrites on $p_{\mathrm{O}_{2}}$ exhibit the characteristic minima reflecting the variation in the oxidation degree of iron ions and the corresponding change in the dominating electron charge carriers. In study [6] it is shown that the total conductivity of ferrites near the minimum can be expressed with good accuracy by the equation:

$$
\sigma\left(T, p_{\mathrm{O}_{2}}\right)=\sigma_{\mathrm{i}}(T)+\sigma_{\mathrm{n}}^{\circ}(T) p_{\mathrm{O}_{2}}^{-1 / 4}+\sigma_{\mathrm{p}}^{\circ}(T) p_{\mathrm{O}_{2}}^{+1 / 4},
$$

where $\sigma_{\mathrm{i}}$ is ion conductivity, which is essentially $p_{\mathrm{O}_{2}}$-independent in the vicinity of $p$ - $n$ transitions due to very small variations of the oxygen nonstoichiometry, $\sigma_{\mathrm{n}}^{\circ}$ and $\sigma_{\mathrm{p}}^{\circ}$ are the partial electron and hole conductivities at unit oxygen pressure. Figure 2 demonstrates, by way of example, the conductivity for some ferrites measured as a function of $p_{\mathrm{O}_{2}}$ at $950^{\circ} \mathrm{C}$, as well as the results of fitting by eq. (4) in the vicinity of the minimum (heavy lines). It is seen that the calculated results are in good agreement with the experiment.

The error of determining the partial contribution parameters to conductivity (table 1 ) is not greater than $1.6 \%, 0.8 \%$ and $2.5 \%$ for $\sigma_{\mathrm{i}}, \sigma_{\mathrm{n}}^{\circ}$, and $\sigma_{\mathrm{p}}^{\circ}$, respectively.

The results in table 1 and the plot demonstrate that the predominant contribution to the conductivity of ferrites is due to electron $(n+p)$ conduction. In this case, oxygen permeability of oxides is determined by the value of ion conduction and it is exactly this characteristic that becomes the target parameter 


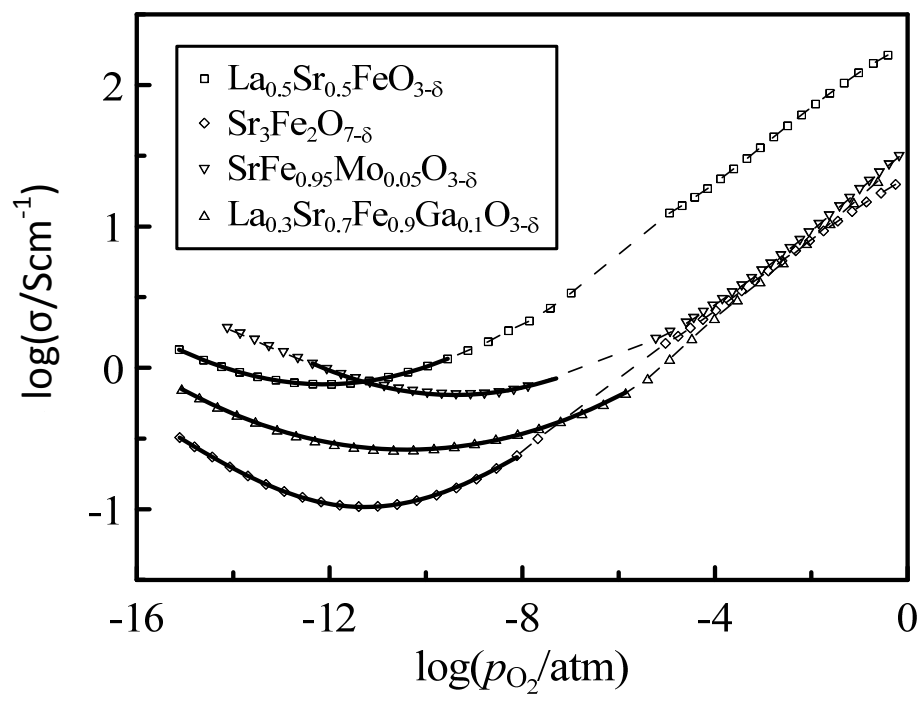

Figure 2: The isothermal plots of total conductivity in some ferrites vs. partial pressure of oxygen at $950^{\circ} \mathrm{C}$. Thick lines show results of fitting by eqn (4).

Table 1: Parameters of the partial ion and electron conductivity in ferrites.

\begin{tabular}{|c|c|c|c|}
\hline Composition & $\sigma_{\mathrm{i}}$ & $\sigma_{\mathrm{n}}^{\circ}$ & $\sigma_{\mathrm{p}}^{\circ}$ \\
\hline $\mathrm{Sr}_{3} \mathrm{Fe}_{2} \mathrm{O}_{7-\delta}$ & $4.35 \cdot 10^{-2}$ & $4.57 \cdot 10^{-5}$ & 19.7 \\
\hline $\mathrm{SrFe}_{0.95} \mathrm{Mo}_{0.05} \mathrm{O}_{3-\delta}$ & 0.406 & $5.27 \cdot 10^{-4}$ & 26.8 \\
\hline $\mathrm{La}_{0.5} \mathrm{Sr}_{0.5} \mathrm{FeO}_{3-\delta}$ & 0.462 & $1.42 \cdot 10^{-4}$ & 161 \\
\hline $\mathrm{La}_{0.3} \mathrm{Sr}_{0.7} \mathrm{Fe}_{0.9} \mathrm{Ga}_{0.1} \mathrm{O}_{3-\delta}$ & 0.195 & $8.7 \cdot 10^{-5}$ & 13.7 \\
\hline
\end{tabular}

in developing novel efficient membrane materials. One of the most promising approaches to creating materials with advanced ion transport characteristics is formation of nano-heterogeneous systems, in which interface transport provides high contribution to conductivity along with intra-grain, bulk contribution. With the use of this approach, the best results were obtained for nano-composites consisting of fusible ion salts and nano-sized powders of chemically stable oxides. For example, the authors of work [7] reported more than a thousandfold increase in ion conduction in $(1-\mathrm{x}) \mathrm{AgI}-\mathrm{xAl}_{2} \mathrm{O}_{3}$ and $(1-\mathrm{x}) \mathrm{RbNO}_{3}-\mathrm{xAl}_{2} \mathrm{O}_{3}$ systems as compared with pure salts. For oxide systems with mixed conductivity, no examples of such considerable enhancement of ion conductivity due to the nano-composite effect are available in the literature since it is difficult to form nano-composites in oxide systems. Nevertheless, some progress was achieved in 
this direction too. In particular, in works $[8,9]$ we have found an original mechanism of in situ formation of nano-heterogeneous systems with enhanced ion conduction based on phase separation of oxides with double-perovskite structure. Using the $\mathrm{SrFe}_{1-\mathrm{x}} \mathrm{Ta}_{\mathrm{x}} \mathrm{O}_{3-\delta}$ system as an example, it was shown that at $x>0.3$ weakly ordered microscopic regions of double perovskite begin to form in the oxide, which are registered by weak superstructure reflections on the electron diffraction spectra in $<\mathrm{h}+1 / 2, \mathrm{k}+1 / 2,1+1 / 2>^{*}$ positions. Arrows in the inset in fig. 3 indicate these reflections.

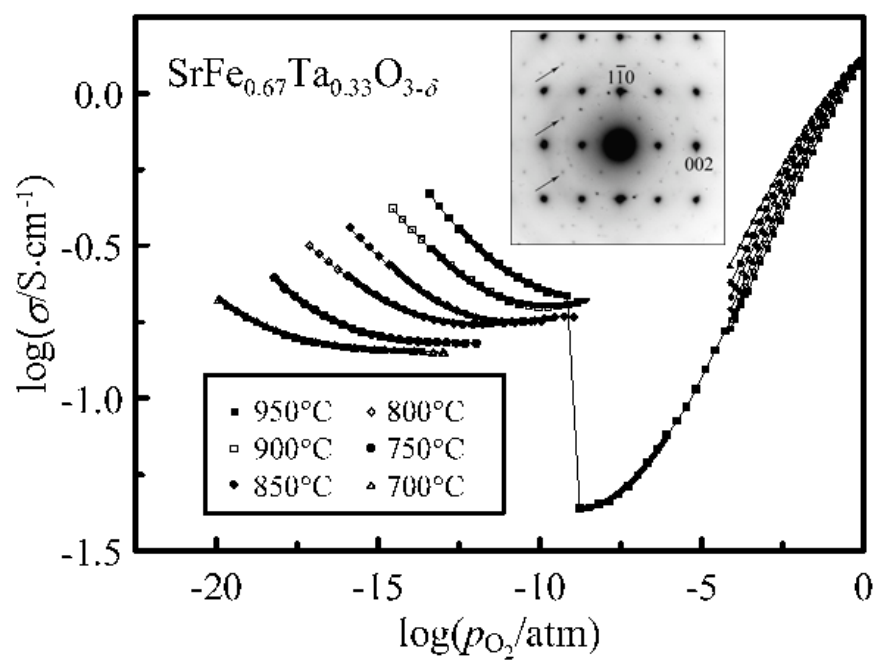

Figure 3: The isothermal plots of total conductivity in $\mathrm{SrFe}_{0.67} \mathrm{Ta}_{0.33} \mathrm{O}_{3-\delta}$ as function of $p_{\mathrm{O}_{2}}$. Insert - electron diffraction pattern. Arrows indicate weak superstructure reflections that correspond to poorly ordered double perovskite.

Removal of oxygen leads to phase separation of the double-perovskite regions: the oxygen-deficient cubic perovskite phase occurs isolated, the doubleperovskite phase grows enriched with tantalum while the degree of ordering of cations in the $B$ sublattice increases. This peculiar phase separation is accompanied by considerable enhancement of conductivity as seen in fig. 3, where the conductivity versus $p_{\mathrm{O}_{2}}$ measurement results for $\mathrm{SrFe}_{0.67} \mathrm{Ta}_{0.33} \mathrm{O}_{3-\delta}$ are given as an example. The results of fitting of eq. (4) to the experimental data in the vicinity of the conductivity minimum (thick solid lines in the plot) suggest that the conductivity jump is solely due to the increase in the ionic contribution to conductivity. The observed effect is explained by the phase separation that gives rise to a developed interface of coherently intergrown nano-sized regions with primitive cubic perovskite and double perovskite structures. According to the theoretical concepts set forth in work [10], a high concentration of interfacial defects and their low binding energy with the crystal lattice may promote rapid 
ion transport; therefore a high volume fraction of interfacial boundaries in the nano-composite materials may appreciably increase ion conduction as is observed in fig. 3. Since the increase of ion conductivity in $\operatorname{SrFe}_{1-\mathrm{x}} \mathrm{Ta}_{\mathrm{x}} \mathrm{O}_{3-\delta}$ is reversible and initial conductivity values are restored at $p_{\mathrm{O}_{2}} \sim 10^{-4}$ atm, this effect is of fundamental rather than of practical importance. Therefore, we evaluated a number of materials in which ion transport is mostly due to bulk diffusion in the crystal for their applicability as oxygen membranes. Using the partial contributions to conductivity in table 1 , the oxygen permeability of $1 \mathrm{~mm}$ thick membranes composed of the corresponding materials was calculated with eq. (3) (fig. 4). It is seen that the bulk oxygen transport in the ferrite $\mathrm{La}_{0.5} \mathrm{Sr}_{0.5} \mathrm{FeO}_{3-\delta}$ is characterized with the maximal flux density. This ferrite was chosen as a basic material for the examination of POM process.

\section{Partial oxidation of methane in membrane reactor}

To examine the membrane materials during partial oxidation of methane, we have developed the extrusion method for the production of tubular ceramic membranes and constructed a test stand. The reactor was a coaxial assembly, whose outer casing was a quartz tube. The membrane unit was connected by a high-temperature sealant with the inlet and outlet corundum tubes thus separating the internal space, through which air was blown, from the external space, in which catalyst was located between the membrane and the quartz casing and where inlet methane feed was supplied. Nickel on porous $\mathrm{Al}_{2} \mathrm{O}_{3}$ carrier was used as a catalyst. The outlet gas from the reactor passed though a dryer and was analyzed with a gas chromatograph. Based on the analysis results, we determined the main characteristics of the POM process: the degree of methane conversion $\left(\left(X_{\mathrm{CH}_{4}}\right)\right.$, selectivity with respect to $\mathrm{CO}\left(S_{\mathrm{CO}}\right)$, hydrogen to CO ratio $\left(\mathrm{H}_{2} / \mathrm{CO}\right)$ and oxygen flux density $\left(\mathrm{J}_{\mathrm{O}_{2}}\right)$ :

$$
\begin{gathered}
X_{\mathrm{CH}_{4}}=\left(1-\frac{x_{\mathrm{CH}_{4}}}{x_{\mathrm{CO}}+x_{\mathrm{CO}_{2}}+x_{\mathrm{CH}_{4}}}\right) \times 100 \% \\
S_{\mathrm{CO}}=\left(\frac{x_{\mathrm{CO}}}{x_{\mathrm{CO}}+x_{\mathrm{CO}_{2}}}\right) \times 100 \% \\
J_{\mathrm{O}_{2}}=F_{\mathrm{d}}^{\text {out }} \times\left(1.5 x_{\mathrm{CO}}+2 x_{\mathrm{CO}_{2}}+x_{\mathrm{O}_{2}}-0.5 x_{\mathrm{H}_{2}}-\frac{0.21}{0.79} x_{\mathrm{N}_{2}}\right) / s
\end{gathered}
$$

Here, $F_{\mathrm{d}}^{\text {out }}$ is the flow of the dry outlet gas, 0.21 and 0.79 are volume fractions of oxygen and nitrogen in air, respectively, $s$ is membrane surface and the last term accounts for nitrogen leaks through microcracks and imperfections in seals. As a result of the systematic studies, the composition and location of the catalyst, the 


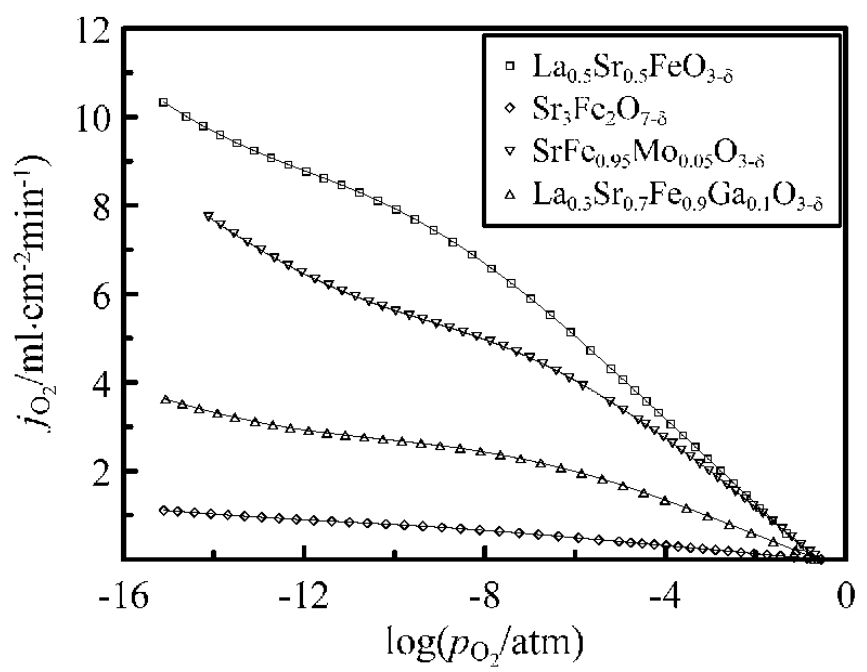

Figure 4: The calculated oxygen flux density through $1 \mathrm{~mm}$ thick membranes of selected oxides at $950^{\circ} \mathrm{C}$ depending on the oxygen pressure at the low-pressure side. The oxygen pressure at the high-pressure side was accepted equal to $0.21 \mathrm{~atm}$.

optimized gas temperature and feed regimes were selected. The successful tests of $\mathrm{La}_{0.5} \mathrm{Sr}_{0.5} \mathrm{FeO}_{3-\delta}$ ceramic oxygen membranes in partial oxidation of methane were carried out at $850^{\circ} \mathrm{C}$ for more than $7000 \mathrm{~h} \mathrm{[11]}$. Besides, it is shown that long-term stability of the membrane can be achieved also at higher temperatures if appropriate materials are used. The results of testing of $\mathrm{La}_{0.5} \mathrm{Sr}_{0.5} \mathrm{Fe}_{0.8} \mathrm{Cr}_{0.2} \mathrm{O}_{3-\delta}$ membrane at $950^{\circ} \mathrm{C}$ are presented in fig. 5. The degree of methane conversion during the whole experiment was not less than $99 \%$. The other parameters of the process, as seen from the figure, were sufficiently steady. The obtained results demonstrate the possibility of developing a new technology of gas processing in principle.

A photograph of a laboratory-scale reactor with a dozen of membrane units is displayed in fig. 6. The facility features an all-metal casing and internal heating. The first tests of this model showed low selectivity $(80 \%)$ and low conversion $(75 \%)$ of the process, as well as relatively small operation efficiency of individual membrane unit in comparison with the one-membrane model. The inspection after the experiments shows that the important condition of high operation efficiency is equal "chemical load" on all membrane units, i.e. equal yield of oxygen to be consumed with equal efficiency for methane conversion. This condition imposes serious requirements on the reactor design, in particular, on the organization of gas flows. Another important factor of efficient reactor 


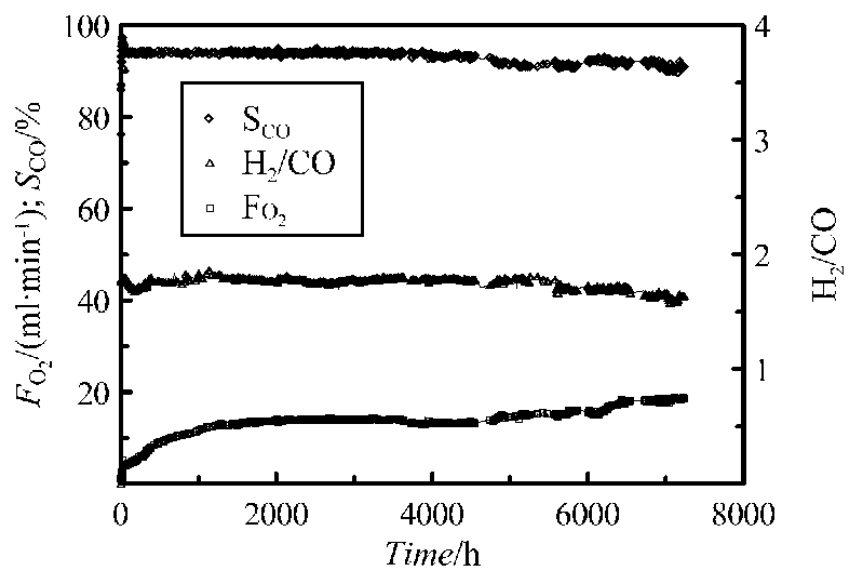

Figure 5: Characteristics of the tubular membrane of $\mathrm{La}_{0.5} \mathrm{Sr}_{0.5} \mathrm{Fe}_{0.8} \mathrm{Cr}_{0.2} \mathrm{O}_{3-\delta}$ in the process of partial oxidation of methane at $950^{\circ} \mathrm{C}$. The surface of membrane is $12.5 \mathrm{~cm}^{2}$; the flow rate of methane is $19 \mathrm{ml} \cdot \mathrm{min}^{-1}$, the flow rate of air is $450 \mathrm{ml} \cdot \mathrm{min}^{-1}$.

operation is uniform temperature distribution in the reaction zone. This condition is difficult to be fulfilled because the exothermal character of methane oxidation in combination with positive temperature coefficient of oxygen permeability leads to temperature instability of the POM process.

If the temperature of one of the membrane units goes up as a result of a fluctuation, this will bring about a local increase in oxygen permeability, enhanced heat generation and progressing temperature rise. To suppress this undesirable effect that hampers the process control, humidified methane was used in the subsequent experiments. From fig. 7 it is seen that this approach made it possible to appreciably improve the process parameters without changing the reactor design. It is seen that at $90 \%$ conversion the selectivity is as much as $80 \%$. As a result, the synthesis gas flow rate at the reactor outlet amounted to about $600 \mathrm{l} / \mathrm{h}$. Although these parameters are far from being perfect and further work is required for improving the process efficiency, the results of the experiments show that the most difficult problems of functioning of POM membrane reactors can be solved in principle and that the process can be scaled up to commercial level output.

\section{Conclusion}

Membranes with mixed oxygen ion and electron conductivity can be used for partial oxidation of methane, with the aim of synthesis gas production. However, to use the MIEC membranes in practice, further studies are required aimed at the development of new materials most suitable for particular applications. Upon 


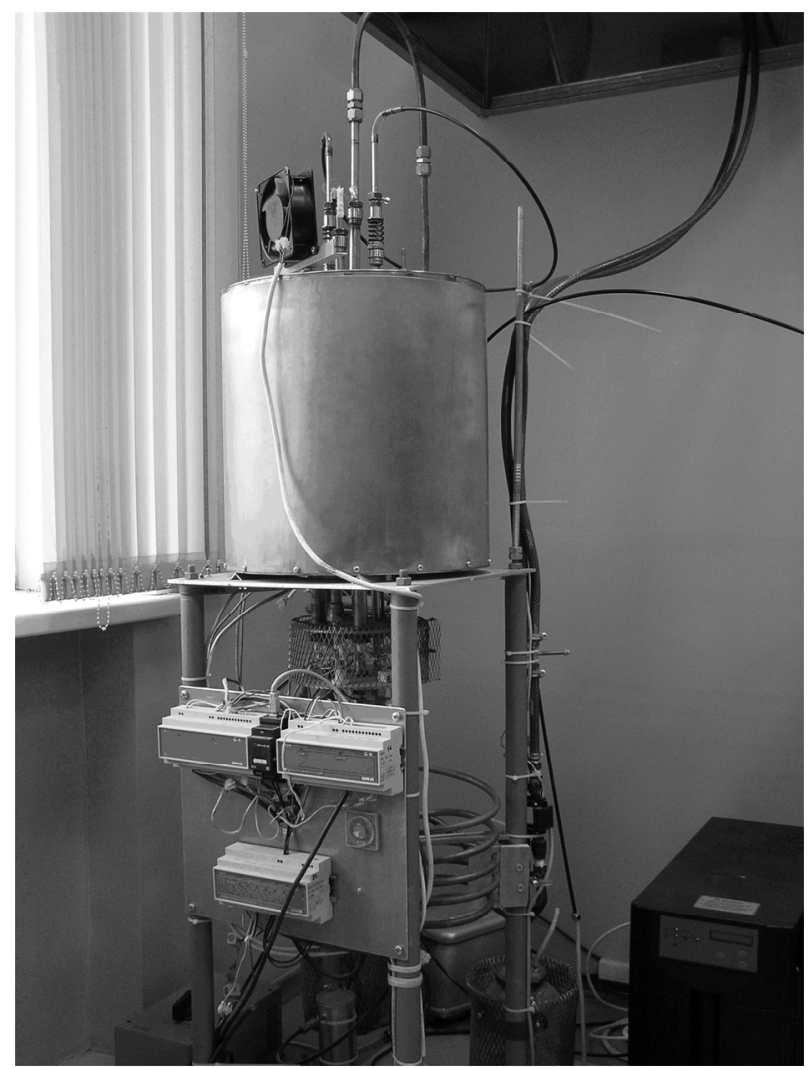

Figure 6: The multi-membrane reactor for partial oxidation of methane.

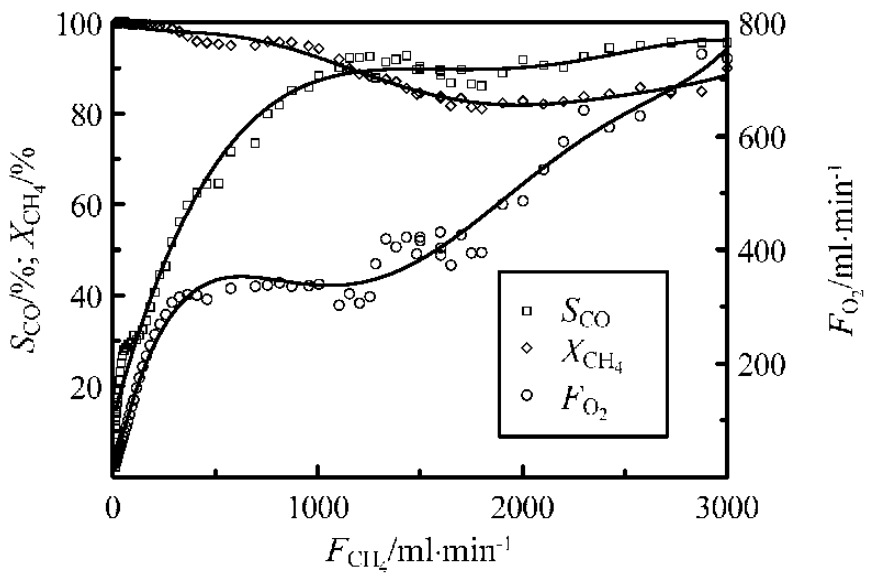

Figure 7: Parameters of the multi-membrane reactor with methane-water feed. 
oxidative conversion of methane to synthesis gas, the membrane material should be chemically stable against action of methane and products of its oxidation. The materials composed of perovskite-like ferrites appear to be quite suitable for these purposes. Development of more practically feasible catalysts has essential significance. Particularly, the problem of suppression of soot formation in the partial oxidation of methane has to be solved along with the problem of designing reactors that would ensure equal oxygen fluxes from all membranes in the reactor assembly and steady yield of synthesis gas from each unit volume of the catalyst. The available results on ceramic membranes with mixed conductivity indicate that they have good potential for industrial applications as a basis for development of compact, cost effective and environmentally safe processes for processing of natural gas.

\section{Acknowledgements}

The work was carried out under financial support of the Government of the Sverdlovsk Region, the Russian Foundation for Basic Research (Project No. 1308-96060-Ural) and the Presidium of the Ural Branch of the Russian Academy of Sciences (Project No. 12-3-2-002-Arctic).

\section{References}

[1] V.S. Arutyunov, O.V. Krylov, Oxidative conversion of methane, Russian Chemical Reviews, 74, pp. 1111-1137, 2005.

[2] H.J.M. Bouwmeester, A.J. Burggraaf, Fundamentals of Inorganic Membrane Science and Technology, Amsterdam: Elsevier, pp. 1-690, 1996.

[3] Y. Teraoka, H-M. Zhang, S. Furukawa, N. Yamazoe, Oxygen permeation through perovskite-type oxides. Chemistry Letters, 14(11), pp. 1743-1746, 1985.

[4] Y. Teraoka, T. Nobunaga, N. Yamazoe, Effect of cation substitution on the oxygen semipermeability of perovskite-type oxides. Chemistry Letters, 17(3), pp. 503-506, 1988.

[5] T. Nakamura, G. Petzow, L.J. Gauckler, Stability of the perovskite phase $\mathrm{LaBO}_{3}(\mathrm{~B}=\mathrm{V}, \mathrm{Cr}, \mathrm{Mn}, \mathrm{Fe}, \mathrm{Co}, \mathrm{Ni})$ in reducing atmosphere I. Experimental results. Materials Research Bulletin, 14(5), pp. 649-659, 1979.

[6] M.V. Patrakeev, I.A. Leonidov, V.L. Kozhevnikov, V.V. Kharton, Ionelectron transport in strontium ferrites: relationships with structural features and stability. Solid State Sciences, 6, pp. 907-913, 2004.

[7] A. Nemudry, N. Uvarov, Nanostructuring in composites and grossly nonstoichiometric or heavily doped oxides. Solid State Ionics, 177, pp. 2491-2494, 2006.

[8] A.A. Markov, E.V. Shalaeva, A.P. Tyutyunnik, V.V. Kuchin, M.V. Patrakeev, I.A. Leonidov, V.L. Kozhevnikov, Structural features and 
820 Energy Production and Management in the 21st Century, Vol. 2

enhanced high-temperature oxygen ion transport in $\mathrm{SrFe}_{1-\mathrm{x}} \mathrm{Ta}_{\mathrm{x}} \mathrm{O}_{3-\delta}$. Journal of Solid State Chemistry, 197, pp. 191-197, 2013.

[9] M.V. Patrakeev, A.A. Markov, E.V. Shalaeva, A.P. Tyutyunnik, E.V. Tsipis, J.C. Waerenborgh, V.V. Kharton, I.A. Leonidov, V.L. Kozhevnikov, Phase separation-promoted ion conduction in $\mathrm{SrFe}_{0.67} \mathrm{Ta}_{0.33} \mathrm{O}_{3-\delta}$ ceramics. Solid State Ionics, 244, pp. 17-22, 2013.

[10] J. Maier, Ion conduction in space charge regions. Progress in Solid State Chemistry, 23, pp. 171-263, 1995.

[11] A.A. Markov, M.V. Patrakeev, I.A. Leonidov, V.L. Kozhevnikov, Reaction control and long-term stability of partial methane oxidation over an oxygen membrane. Journal of Solid State Electrochemistry, 15, pp. 253-257, 2011. 